\title{
Preceding operational capabilities as antecedents for productivity and innovation performance
}

\author{
Minna Saunila ${ }^{1}$ (D) $\cdot$ Juhani Ukko $^{1} \cdot$ Tero Rantala $^{1} \cdot$ Mina Nasiri $^{1}$. \\ Hannu Rantanen ${ }^{1}$
}

Published online: 20 November 2019

(c) The Author(s) 2019

\begin{abstract}
This study focuses on the connections among operational capabilities, productivity, and innovation performance. Specifically, the study investigates whether preceding operational capabilities, particularly human, time management, and financing capabilities, affect total productivity, labor productivity, and innovation performance. Using data from 203 Finnish small- and medium-sized enterprises, this study shows that human and time management capabilities affect total productivity, whereas only human capabilities affect labor productivity. Both human and time management capabilities affect innovation performance. Hence, this study makes two main contributions to existing research on operational capabilities. As a first contribution, the study introduces three preceding operational capabilities-human, time management, and financing capabilities - as crucial elements to realize operational resources and practices, on one hand, and to establish operational capabilities, on the other hand. As a second contribution, this research adds to the literature a comprehensive investigation of the links of preceding operational capabilities with productivity (i.e., total productivity and labor productivity) and innovation performance.
\end{abstract}

Keywords Productivity $\cdot$ Innovation performance $\cdot$ Operational capabilities $\cdot$ Human capabilities · Time management capabilities · Financing capabilities

JEL Classification M1 $\mathrm{O} 3$

\section{Introduction}

Economic growth depends on innovation and new operational approaches to improve products, services, and processes (Prieger 2007; Peng et al. 2008). Innovation and productivity development are considered to be especially important

Minna Saunila

minna.saunila@lut.fi

1 LUT University, Mukkulankatu 19, 15210 Lahti, Finland 
factors in economic growth and consequently receive heavy attention from academics, industry representatives, and policymakers seeking to develop policies to promote innovation performance and productivity (Mazzucato 2013; Piening and Salge 2015). One key focus is the role of operational capabilities in enhancing innovation performance and productivity (e.g., Mazzucato 2013; Mina et al. 2013).

Amid much discussion of the importance of operational capabilities to competitive success, terms such as capabilities (Eisenhardt and Martin 2000; Lee and Kelley 2008), resources (Tu et al. 2006), and best practices (Maire et al. 2005; Ulusoy and Ikiz 2001) are used interchangeably although they refer to very different concepts (Flynn et al. 2010). Wu et al. (2010) explain that confusion about what operational capabilities are and what differentiates them from resources and practices exists because these factors are closely related, and the impacts of operational capabilities can largely be attributed to resources and operational practices, believed to be critical sources of capabilities (Peng et al. 2008). This process approach reflects the view that operational capabilities should be viewed as means to end rather than as ends themselves (Swink and Hegarty 1998). Similarly, Flynn et al. (2010, p. 248) define operational capabilities as "firm-specific sets of skills, processes, and routines, developed within the operations management system, that are regularly used in solving the problems faced by a unit and which provide that unit-and, ultimately, the firm-with the means of configuring the resources of the operations management system to meet the firm's distinctive needs and challenges."

Operational capabilities are suggested to give unity, integration, and direction to resources and operational practices by providing both explicit elements (e.g., resources and practices) and tacit elements (e.g., know-how, skill sets, and leadership) for handling various problems and uncertainties (Flynn et al. 2010; Wu et al. 2010). Resources can be tangible (e.g., financial and physical resources), intangible (e.g., technology, reputation, and culture), and human (e.g., specialized skills and knowledge, communication, and motivation) (Wu et al. 2010). Operational capabilities draw on resources and operational practices to generate outcomes consistent with the desired results (Flynn et al. 2010; Wu et al. 2010).

According to Teece et al. (1997), in general there are two sets of capabilities at firms; the first set of capabilities is related to converting inputs into outputs, while the second set of capabilities refer to changing other firms capabilities. The first set is called operational capabilities, which are static in the sense that they cannot change by their own unless they are acted by other capabilities (Dangol and Kos 2014). Because of the static nature of operational capabilities and inability to change by their own, there is a need for identifying other types of capabilities to assist integrating, reconfiguring and updating existing operational capabilities to adopt environmental transitions (Dangol and Kos 2014). Thus, this study focuses on preceding operational capabilities, which are a subset of operational capabilities, to investigate and understand their importance in achieving higher productivity and innovation performance. Distinction between operational capabilities and preceding operational capabilities is necessary, because operational capabilities are directly involved with firm performance (Dangol and Kos 2014; Helfat and Winter 2011), while preceding operational capabilities are indirectly connected to firm performance by integrating, reconfiguring and updating existing operational capabilities. Thus, clear distinction 
between operational capabilities and preceding operational capabilities could facilitate implementation of operational capabilities to achieve competitive advantages for firms.

In this study, the realization of resources and practices, particularly human, time management, and financing capabilities, are considered to be critical preceding operational capabilities, each consisting of a bundle of interrelated routines that become capabilities when utilized successfully (Teece et al. 1997). Human capabilities refer to labor commitment to operate effectively in firm processes. Having human capability requires the ability to exploit resources, such as specialized skills, knowledge, communication, and motivation (Wu et al. 2010), in a way that directs employees' behavior toward the desired attitudes for operational development. Time management capabilities refer to the ability to allocate sufficient time for the appropriate development of operations, decision-making activities, and analysis of productivity measurement results (De Toni and Meneghetti 2000). Financing capabilities refer to the ability to find proper financing opportunities and invest appropriate amounts for the desired operational development (Gabrielsson et al. 2004; Wu et al. 2012). Prior research shows that these capabilities are connected to the achievement of firm goals, which guides the selection of the studied capabilities (e.g., Jiang et al. 2012; Demeter 2013; Mazzucato 2013). So far, no study has investigated the relationships of the three preceding operational capabilities with productivity and innovation performance. Using data from 203 Finnish SMEs, the current study empirically tests whether these three preceding operational capabilities affect total productivity, labor productivity, and innovation performance.

The remainder of this paper is organized as follows. In Sect. 2, key terms concerning preceding operational capabilities, productivity, and innovation performance are established. In Sect. 3, the related literature is reviewed, and the hypotheses are developed. The research methods and data collection are described in Sect. 4, while Sect. 5 presents the results, which are further discussed in Sect. 6.

\section{Conceptual framework}

\subsection{Preceding operational capabilities: an overview}

Operational capabilities are considered to be the firm's capability to perform functional activities using purposefully chosen groups of resources (Protogerou et al. 2011). To attain and sustain competitive advantages, effective operational capabilities are necessary. Wu et al. (2012) show that operational capabilities are heavily studied from the perspective of outcomes, including cost, quality, dependability, speed, and flexibility (e.g., Ferdows and De Meyer 1990; Flynn and Flynn 2004). $\mathrm{Wu}$ et al. (2010) accordingly focus on the process approach and develop a taxonomy of six emergent operational capabilities: operational improvement, operational innovation, operational customization, operational cooperation, operational responsiveness, and operational reconfiguration. Operational capabilities can also be viewed 
as resource reconfiguration, that is, the process of investing in or divesting resources depending on the changing environment (Teece et al. 1997; Wu et al. 2012).

As defined in the introduction, preceding capabilities consist of the ability to exploit resources, such as time, money, and motivation (De Toni and Meneghetti 2000; Gabrielsson et al. 2004; Wu et al. 2010, 2012), in a way that improves productivity or generates greater innovations. Drawing on the prior studies (e.g., De Toni and Meneghetti 2000; Gabrielsson et al. 2004; Wu et al. 2010, 2012), the study considers human, time management, and financing capabilities to be critical preceding operational capabilities. Preceding operational capabilities are considered to be a subset of operational capabilities as this study investigates and understands their importance in achieving higher productivity and innovation performance. Next, specific preceding capabilities studied are defined.

\subsubsection{Human capabilities}

The firm's behavioral environment involve[s] the firm's organizational culture and management commitment - that is, the attitudes, values, experiences, and managerial approaches that define and guide the corporate effort (de Brentani and Kleinschmidt 2004, 2015; Ukko et al. 2017). Operational capabilities affect the resources, practices, and competences that enable the organization to perform and to gain competitive advantages (e.g., strategic alignment and organizational learning) (cf. Flynn et al. 2010; Wu et al. 2010, 2012), so the human capability of firm's entire labor force is an integral part of it. Here, human capabilities are defined as labor commitment to operate effectively within firm processes. For our discussion of the role of human capabilities in productivity and innovation performance, we focus on the type of commitment manifested through labor attitudes toward developing firm operations. These operations-related attitudes of humans (e.g. Maloney 1983) are important prerequisites for well-functioning operations. The concept of commitment allows further insight into human capability as it suggests that operations-related attitudes are crucial conditions for human capabilities.

\subsubsection{Time management capabilities}

Effective operational capabilities enable firms to exploit opportunities without extra costs and time, organizational disruption, and loss of performance (Protogerou et al. 2011). Time, therefore, is an important component of operational capabilities, and managers should consider time in their decisions (Mitchell and James 2001). The value of time in finding appropriate solutions for various challenges might change based on the context, making time management an essential capability for firm managers to identify and solve problems (Ritala et al. 2016).

Furthermore, rapid changes in technology, markets, and everyday life increased the importance and value of time in operations as firms seek to become winners in highly competitive business environments (Demeter 2013). Accordingly, the term time-based competition was introduced in the 1990s by Stalk and Webber (1993) in research on firm operations based on speed. These operations include strategies related to decision-making, implementation of management programs, and different 
operations throughout the lifecycle, including the integration of product and process design and development, which speeds up time to market, manufacturing, and logistics times (Demeter 2013). However, rushing development of operations without exploiting opportunities might threaten firm success (De Toni and Meneghetti 2000; Stalk and Webber 1993) due to difficulties in investment returns (Demeter 2013). It, therefore, is necessary to consider allocating sufficient time for operations development and decision-making activities, such as implementing and analyzing productivity measurement results. In this study, time management capabilities refer to the firm's capability to arrange sufficient time for operations, decision-making, and analysis of productivity measurement results.

\subsubsection{Financing capabilities}

Financing capabilities constitute an important component of the firm's business and development activities. Wu et al. (2012) propose that under the umbrella of operational strategies and practices, operational capabilities represent different but related investment decisions regarding how to expend limited resources. According to them, a main challenge in operations strategy development is to identify the investments that best support the overall business strategy. With firms' limited financial resources, managers must compare and consider various investments. In addition to allocation of internal resources, the development and improvement of productivity (e.g., investments in new devices and factors) also requires external funding in many cases. Although firms use both internal and external money to finance their growth, productivity development, and innovation activities, securing available external funding often seems to be difficult. Lee et al. (2015) note that innovative firms are more likely to be turned down for financing than other firms, and this trend increases during financial crises. It is commonly argued that firms must use different funding patterns and utilize their financing capabilities to support their growth, development, and innovation activities. In today's continuously changing business environments, firms need dynamic financing capabilities (Teece et al. 1997; Löfsten 2016; Xiang et al. 2018); in other words, they need new financial information and opportunities to renew and change their resource base when needed (Eisenhardt and Martin 2000; Gabrielsson et al. 2004). Thus, in this study, financing capabilities refer to the firm's capability to find proper financing opportunities and invest appropriate amounts in needed development of operations.

\subsection{Productivity and innovation performance}

\subsubsection{Productivity}

Productivity refers to the relationship between the outputs generated by a system and the inputs necessary to create those outputs (Sink 1985). Many papers address total factor productivity and the productivity of individual inputs and certain fields of business (e.g., Jerzmanowski 2007). Jacobs et al. (2016) use the term operational productivity to describe a variety of manufacturing inputs (e.g., labor, facilities, 
equipment, and inventory) operations managers control to maximize firm outputs. This definition of operational productivity has a larger scope than labor productivity but neglects aspects of firm operations outside manufacturing. In this study, therefore, the productivity concept is divided into total productivity and labor productivity. Total productivity refers to the productivity of firm operations in general, while labor productivity is a more specific term describing the quality of labor efforts (e.g., Kurosawa 1991; Tangen 2005).

\subsubsection{Innovation performance}

Conceptualizations of innovation can be divided into two categories: those related to innovation as a process and as an outcome (Crossan and Apaydin 2010; JiménezJiménez and Sanz-Valle 2011; Saunila and Mäkimattila 2018). In general, innovation demands the development and implementation of creative ideas in products, processes, services, and organizational arrangements (Schumpeter 1934). In this study, innovation performance is used to describe innovation as an outcome whose success is determined by multiple aspects or inputs dedicated to the creation of innovation. The inputs can be tangible (e.g., people, money, time, and equipment) or intangible (e.g., motivation, knowledge, and organizational culture) (Davila et al. 2012). Saunila and Ukko (2014) report similar findings than Davila et al. (2012) concerning management structures, employee roles and attitudes, and the ability to renew or adapt to changing operating environments. Innovation performance thus refers to the successful implementation of employees' ideas, external information, and new technologies, as well as the ability to renew and change internal operations.

\section{Hypotheses development}

\subsection{Operational capabilities as antecedents of total productivity}

Research shows the importance of human capabilities for the firm (Barney and Wright 1998; Ukko et al. 2007, 2017; Fonseca et al. 2018). Human capabilities, as a measure of labor's commitment to operating effectively within firm processes, therefore, are considered to be an important element in total productivity. Firm employees aim to increase their productivity by learning new skills or applying knowledge to their jobs (Onkelinx et al. 2016). Through this commitment to developing new abilities, human capabilities provide a foundation for performance (cf. Ployhart et al. 2011; Abolhassani et al. 2019). For example, Collins and Smith (2006) suggest that commitment created through human resources (HR) practices can improve firm performance by increasing employees' willingness to work together to create and exchange knowledge. Tornow and Wiley (1991) find that employee attitudes, such as job satisfaction, influence firm performance.

In sum, human capabilities can be viewed as labor commitment-manifested in labor attitudes-to operate effectively within firm processes. Due to the importance of labor attitudes (Jiang et al. 2012; Melián-González 2016) and commitment (Collins and Smith 2006) in organizational and job performance, 
a relationship among human capabilities on total productivity is proposed. Based on the literature review and these arguments, we propose the following hypothesis:

H1a: Human capabilities are positively related to total productivity.

Much research demonstrates that time can serve as a competitive weapon for firms operating in global markets (Demeter 2013). Accelerating firm operations is not always possible due to limitations (e.g., physical rules and economic justifications) to speeding up all business processes (Blackburn 2012). Faster operations are not always profitable, and some operations need sufficient time to be profitable. Therefore, time management capabilities, or the ability to allocate sufficient time for different operations (e.g., the development, implementation, and analysis of performance measurements) are considered to be a key element in total productivity. According to Kacperczyk et al. (2014), managers with time management skills can successfully navigate markets even amidst recessions. Time management capabilities, therefore, provide economic value for investors (Liao et al. 2017).

Based on by Demeter's (2013) results, firms that compete based on time have higher operational performance (e.g., productivity, flexibility, reliability, and time to market) and business performance (e.g., sales, market ratio, and return on investment) than those ones that do not. Johnston et al. (2002) argue for the importance of performance measurements in improving business performance based on three points. First, understanding both the drivers and the results of each activity is necessary for managers at all levels of firms. Second, understanding the relationship between the drivers and the results is important. Third, performance measures have potential to support firms' strategic intentions. To be productive, therefore, it is necessary that managers have the capability to manage their time and allocate enough time to implement and analyze performance measurement results, especially productivity measures. In sum, time management capabilities can increase the total productivity of a firm. Based on the literature review and these arguments, we suggest the following hypothesis:

H1b: Time management capabilities are positively related to total productivity.

Firms' total productivity might be affected by financing challenges, such as investments in fixed assets, including factories, buildings, and machines. Challenges to fixed-asset investments risk the ability to meet the cash requirements for daily production and service operations (Karadag 2015), making the ability to arrange financing for operations crucial. Regarding this financing capability, Restuccia and Rogerson (2013) argue that credit market imperfections are one of the most studied channels that lead to misallocation, resulting in low total productivity. They note that, despite differences in previous studies, credit market imperfections are generally believed to possibly cause both selection and misallocation effects. Specifically, credit constraints may prevent the accomplishment of productivity improvements in organizations. Other studies (cf. Amaral and Quintin 
2010; Buera et al. 2011) explore the effects of various finance market imperfections on total productivity. According to Restuccia and Rogerson (2013), a main finding in this literature is the persistence of total productivity differentials and firms' ability to overcome credit market constraints through self-financing (e.g., Banerjee and Moll 2010). Vos et al. (2007) further show that high-growth firms participate more in loan markets than low-growth firms.

In addition to private credit market financing possibilities, growing types of public financial programs support and promote firms' productivity, competitiveness, employment, and sustainable growth (Barbosa and Silva 2018). Although many such programs aimed at reducing market failures and development risks offer firms low-interest-rate loans and cash grants, Barbosa and Silva (2018) indicate that firms lacking capabilities and resources seem to face the largest obstacles obtaining public funding support. In sum, financing capabilities can be viewed as the ability to arrange financing for firm development activities and daily businesses, and these capabilities can enhance firms' total productivity. Based on the literature review and these arguments, we suggest the following hypothesis:

H1c: Financing capabilities are positively related to total productivity.

\subsection{Operational capabilities as antecedents of labor productivity}

High commitment to firm operations is proven to result in higher job satisfaction and performance (Ployhart et al. 2011; Latorre et al. 2016; Abolhassani et al. 2019). Labor productivity generally reflects the quality of labor efforts, so it likely is affected by human capabilities. For example, Berglund and Karltun (2007) study production scheduling and suggest that human capabilities that cannot be automated significantly influence production operations. In this way, human capabilities serve as a foundation for the development of additional skills and abilities through jobrelated training (Ployhart et al. 2011). Also, Latorre et al. (2016) find that training practices that support labor commitment positively affect job performance.

Based on this explanation, commitment to operating effectively within firm processes - in other words, having human capabilities — can be seen as necessary to develop labor productivity. Also, research suggests that human capabilities enhance different areas of job performance (e.g., Berglund and Karltun 2007; Latorre et al. 2016; Ukko et al. 2017). To achieve commitment, labor must have favorable attitudes toward developing firm operations, and such an environment promotes labor productivity. We, therefore, formulate the next hypothesis:

H2a: Human capabilities are positively related to labor productivity.

In addition to human capabilities, time management capabilities are important to increase labor productivity. Time is a crucial resource for managers, and they should observe organizational issues through the lens of time. Effective managers handle their time effectively and create benefits through time management. Reunanen (2015) shows that employee productivity and firm performance heavily rely on how time is managed in various operations (Reunanen 2015). Sanchez and Terlizzi (2017) note that managers can succeed if they deliver projects on time and within 
scope and budget. By completing projects on time, firms can increase productivity by controlling the cost of human resources (Chan et al. 2008).

Controlling operations is an important activity to improve performance. Measuring and analyzing is a prerequisite to controlling operations. Due to the importance of controlling operations to achieve higher performance, it is necessary for firms to measure their activities and analyze the results (Goshu et al. 2017). Moreover, successful productivity management heavily depends on the participation of both managers and employees (Goshu et al. 2017). Consequently, employing workers who have the skill to manage their time while implementing and analyzing productivity measurements becomes very important. Time management capabilities thus are found to enhance different areas of job performance and to likely affect labor productivity. We, therefore, hypothesize the following:

$\mathrm{H} 2 \mathrm{~b}$ : Time management capabilities are positively related to labor productivity.

Studies also indicate that financing capabilities are connected to labor productivity. At the firm level, research investigates the impact of human resource management on organizational productivity (Huselid 1995). Holzer (1987) notes that extensive recruiting efforts can increase productivity, but firms may also need external or internal financing for employee recruitment, for instance, during high-demand seasons. De Winne et al. (2018) show that through labor turnover, firms lose valuable human capital, decreasing returns from investments in human capital (e.g., firmspecific training) and ultimately undermining competitive advantages and productivity (Shaw et al. 2013). Replacing employees who leave with workers possessing the same level of human capital requires substantial investments of both time and money (De Winne et al. 2018). Consequently, financing capabilities are needed to improve labor productivity through setting wages and developing compensation systems. Wages are important to labor productivity; indeed, De Negri et al. (2011) and Castillo et al. (2014) use wages as a factor in labor productivity. Previous research on productivity improvement also recognizes links between employee compensation systems and productivity (Gerhart and Milkovich 1992). Financing capabilities, therefore, are needed to implement high-performance working practices associated with lower employee turnover and improved labor productivity and corporate financial performance. In sum, financing capabilities are found to enhance different areas of job performance and thus likely affect labor productivity. We, therefore, hypothesize the following:

H2c: Financing capabilities are positively related to labor productivity.

\subsection{Operational capabilities as antecedents of innovation performance}

The enhancement of human capabilities can also be reflected in innovation performance (cf., Koufteros et al. 2014; Saunila 2017; Morris 2018). Previous research on human capabilities investigates a variety of innovation predictors. For example, Del Canto and Gonzalez (1999) suggest that human capabilities, including employees' qualifications such as high skill levels and knowledge of 
the firm, assist in realizing research and development activities, which, when successful, can improve innovation performance. In addition to labor skills, the quality of commitment is studied. For instance, Saunila and Ukko (2014) suggest that human capabilities are related to employee commitment and affect innovation performance. Also, labor-commitment-related QM practices contribute to creating learning-oriented firms that support the successful development of new products (Gutierrez-Gutierrez et al. 2018). Viewing commitment as a manifestation of labor attitudes, Hernandez-Espallardo et al. (2018) find that labor's jobrelated attitudes play a significant role in creating an innovation culture, which acts to create value and improve performance. Based on the literature reviewed, human capabilities likely affect innovation performance. The following hypothesis, therefore, is formed:

H3a: Human capabilities are positively related to innovation performance.

Managers cannot ensure innovation performance without time management capabilities. Different arguments about the impact of speed on innovation performance are in circulation (Adams-Bigelow and Griffin 2005; Kessler and Bierly 2002; Chen et al. 2012). Some researchers describe positive impacts from speed on innovation performance (Calantone et al. 2003; Carayannis and Alexander 2002), whereas others find only limited support for this claim (Adams-Bigelow and Griffin 2005; Kessler and Bierly 2002). Time pressures in the development of operations might cause some problems, such as skipping vital steps, ignoring technical risks, and creating market uncertainty (Chen et al. 2012). It, therefore, is essential to allocate operations sufficient time to increase innovation performance.

Fast decision-making might become a trap if it becomes perceived as a requirement, forcing decision-making that could result in failure, especially in start-up firms (Perlow et al. 2002). Ancona and Chong (1996) demonstrate that speeding up some firm activities is ineffective due to the lack of alignment between the firm's pace and the external environment. However, Eisenhardt (1989) shows that in high-speed environments, faster decision makers perform better at using information and developing operations than slower decision makers. Thus, time is a basic resource in operational development that, if used efficiently and effectively, improves firms' innovation performance. According to Ellwood et al. (2017), efficient and effective use of time requires accelerating innovation performance in firms. It, therefore, is important to improve time management capabilities and allocate sufficient time to plan operations in projects in order to enhance innovation performance. Based on this literature review, time management capabilities, as an element in preceding operational capabilities, are shown to affect innovation. The following hypothesis, therefore, is proposed:

H3b: Time management capabilities are positively related to innovation performance.

Financing capabilities are also considered to be key to manage innovation (e.g., Mazzucato 2013; Mina et al. 2013). According to Mazzucato (2013), 
long-term strategic commitments to innovation require specific types of financing, and different types of innovation activities may require firms to use either internal or external financing mechanisms. For instance, Mina et al. (2013) find that product - and especially process - innovation tends to attract external capital, but organizational innovation does not. In addition to external loan mechanisms, firms' innovation activities draw support from government financing mechanisms, such as tax incentives (d'Andria and Savin 2018; Grilli et al. 2018). Although different types of mechanisms and sources are available to finance firms' innovation (Lv et al. 2018), firms need understanding and capabilities to be able to finance their innovation activities. Based on this literature review, preceding operational capabilities in finances are shown to affect innovation. The following hypothesis, therefore, is formulated:

H3c: Financing capabilities are positively related to innovation performance.

\subsection{Research model}

So far, no study has investigated the relationships of the three preceding operational capabilities with productivity and innovation performance. According to the previous sections, human, time management, and financing capabilities can be viewed as distinct preceding operational capabilities. In our model, we differentiate preceding operational capabilities from resources and practices, although they are closely related. Preceding operational capabilities reflect the successful manifestation of resources, so they are firm-specific, operations-based capabilities necessary to gain competitive advantages via operational capabilities. Preceding operational capabilities, therefore, are based on firms' accumulation of realized resources and practices that develop unique capabilities within operational capabilities, which, in turn, contribute to productivity and innovation performance. Figure 1 shows the model of the theoretical relationships among preceding operational capabilities, productivity (total productivity and labor productivity), and innovation performance.

\section{Methodology}

\subsection{Sample and data gathering}

Empirical data for the study was collected from Finnish SMEs through a web-based survey. SMEs (firms employing 10-249 employees) were selected as a population of this study due their significance in the Finnish economy. $99.8 \%$ of the Finnish enterprises are SMEs and they produce about half of the turnover of all firms. (The Federation of Finnish Enterprises) In total, 3662 SMEs with revenue of 2-50 million euros and 10-249 employees were included in the randomly selected sample. With Finland's population of approximately 20,000 SMEs, the sample comprised approximately $18.3 \%$ of all firms in the targeted category. After the questionnaire was sent to potential respondents (meaning managers of the sampled 3662 firms), a reminder was sent one week later. Of the 2989 questionnaires sent, 673 were returned to the 


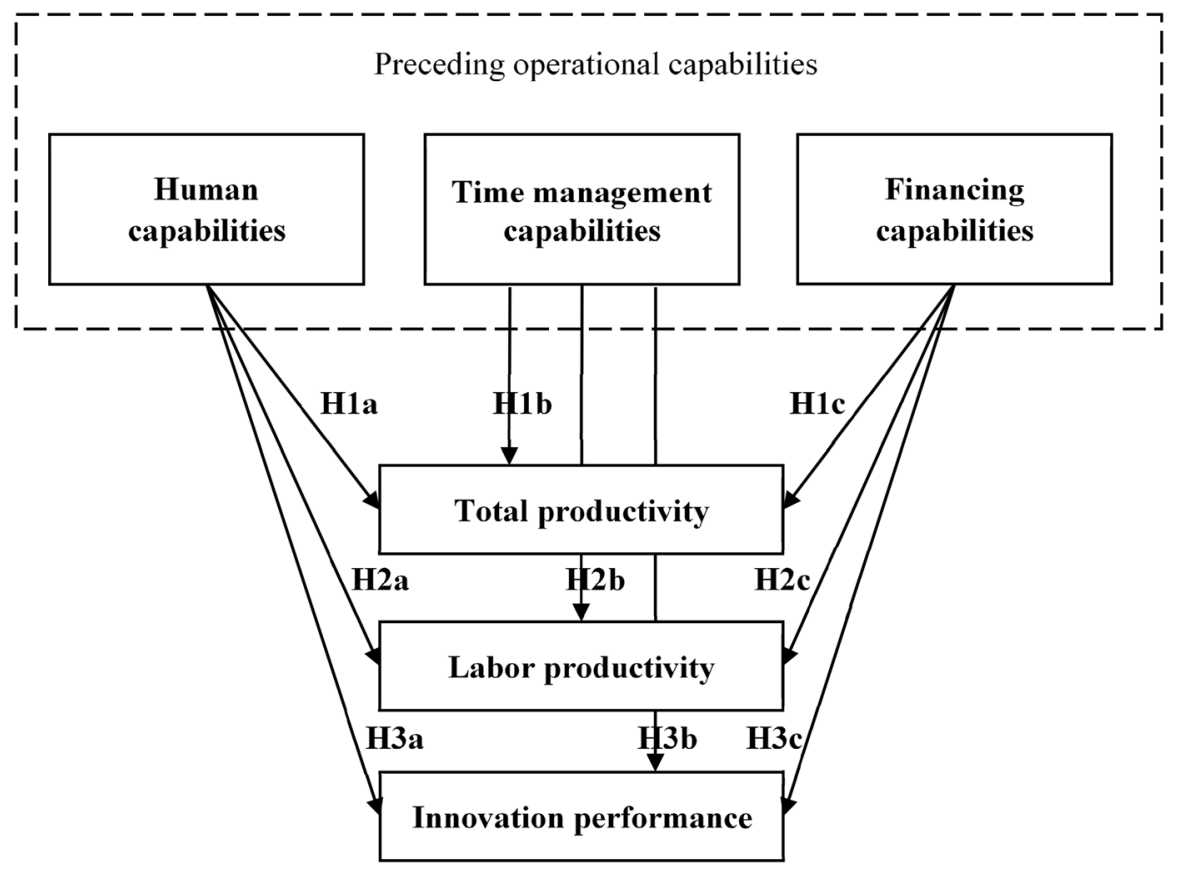

Fig. 1 Research model and hypotheses

researchers with return-to-sender messages, indicating that the recipients' addresses were no longer valid. Afterwards, the data was cleaned. Response was deleted if most of the items included missing values, or if the responses were advisedly flawed (for example the best possible value chosen for each item). This process resulted that a total of 203 valid responses was received, resulting in a response rate of $6.8 \%$.

The demographics are presented in Table 1 . The data were categorized by the revenue of the firms in which the respondents worked. Roughly $58.6 \%$ of the respondents were employed by small firms, while $27.6 \%$ worked for medium-sized firms. About $13.8 \%$ of the respondents did not want to provide their firms' revenue. Regarding firm size, as measured by number of employees, $52.7 \%$ of the firms were considered to be small, with fewer than 50 employees, while around $31.5 \%$ of the firms had more than 50 employees. About $15.8 \%$ of the respondents did not answer this question. Nearly half (47.8\%) of the sample represented manufacturing firms, and $43.4 \%$ of the responding firms were service oriented. About $8.9 \%$ of the respondents did not respond. In addition, the sample covered a variety of different types of business as shown in Table 1 .

\subsection{Non-response bias}

Non-response bias was assessed by testing for differences between the respondents that did and did not fully complete the survey (Whitehead et al. 1993). Tests of the 
Table 1 Background of the respondents

\begin{tabular}{|c|c|c|}
\hline & $\mathrm{n}$ & $\%$ \\
\hline \multicolumn{3}{|l|}{ Revenue (Meuro) } \\
\hline 10 or less & 119 & 58.62 \\
\hline 11 or more & 56 & 27.59 \\
\hline No response & 28 & 13.79 \\
\hline \multicolumn{3}{|l|}{ No. of employees } \\
\hline 49 or less & 107 & 52.71 \\
\hline 50 or more & 64 & 31.53 \\
\hline No response & 32 & 15.76 \\
\hline \multicolumn{3}{|l|}{ Firm type } \\
\hline Manufacturing & 97 & 47.78 \\
\hline Service & 88 & 43.35 \\
\hline No response & 18 & 8.87 \\
\hline \multicolumn{3}{|l|}{ Business type } \\
\hline Industry & 75 & 36.95 \\
\hline Construction & 26 & 12.81 \\
\hline Wholesale and retail & 18 & 8.87 \\
\hline Information and communication & 12 & 5.91 \\
\hline Logistics & 9 & 4.43 \\
\hline Healthcare services & 8 & 3.94 \\
\hline Environmental & 5 & 2.46 \\
\hline Energy services & 4 & 1.97 \\
\hline Agronomy/forestry/fishery & 3 & 1.48 \\
\hline Other & 11 & 5.42 \\
\hline No response & 32 & 15.76 \\
\hline \multicolumn{3}{|l|}{ Position } \\
\hline Executive & 177 & 87.19 \\
\hline White-collar worker & 2 & 0.99 \\
\hline Blue-collar worker & 2 & 0.99 \\
\hline No response & 22 & 10.83 \\
\hline
\end{tabular}

means of the constructs and the means of the items revealed no significant differences at the 5\% significance level (p-values $0.123-0.768$ ). The study results, therefore, were not influenced by non-response bias.

\subsection{Common method bias}

Common method bias can interfere with results from research using a single respondent from a firm. Several procedural remedies were used to minimize the potential for such bias (Podsakoff et al. 2003). The respondents were encouraged to answer the items as truthfully as possible and were allowed to remain anonymous. These measures decreased the likelihood that the respondents gave answers believed to be viewed favorably by others (i.e., social desirability). Attention was also paid to 
the construction of the items, which could reduce common method bias. In addition, methodological separation was applied (Craighead et al. 2011) by employing different variations of Likert-type scales, such as "very significant/not at all significant" and "strongly disagree/strongly agree." Additionally, Harman's single-factor test (Podsakoff et al. 2003) was performed. All the variables were loaded into exploratory factor analysis, and the unrotated factor solution was analyzed. If one general factor accounts for most of the covariance of the measures, then common method variance exists. In this case, the main factor explained only $32.6 \%$ of the total variance, indicating that no significant common method variance existed (Podsakoff et al. 2003).

\subsection{Variable measurement}

This study followed a survey-based approach and utilized managerial assessment of preceding operational capabilities, total productivity, labor productivity, and innovation performance in the respondents' firms. Thus, the respondents provided evaluations of the constructs in their firm, and the responses to the survey items required adequate knowledge of firm operations. Managers were selected as the respondents because they were expected to have this knowledge. The items measuring theoretical constructs were developed based on the literature review. When existing items were not identified, the researchers relied on the literature to specify the content of constructs. The target firms were SMEs, so the items were selected based on relevance to the SME context.

Preceding operational capabilities were captured with a new scale (informed by previous research, as presented in Table 2) with three components: human, time management, and financing capabilities. Human capabilities, defined as labor commitment (manifested in attitudes) to operate effectively within firm processes, were operationalized via a three-item scale addressing the attitudes of different personnel groups in the firm toward developing operations. Time management capabilities were also measured with a new scale with four items addressing whether there was enough time for tasks related to operations management. The financing capabilities scale consisted of three new items measuring the sufficiency of financial resources and their allocation to operational development.

The dependent variables were total productivity, labor productivity, and innovation performance. Total productivity and labor productivity were measured with single items. Although some scholars criticize single-item measures due to reliability and validity problems (Sarstedt and Wilczynski 2009; Diamantopoulos et al. 2012), their use is acceptable under certain conditions. Single-item measures can be used when the research setting includes concrete, singular objects and attributes (Bergkvist and Rossiter 2007, 2009) that are homogenous (Loo 2002) and unambiguous to the respondents (Sackett and Larson 1990), as was the case in this study. Innovation performance was measured with five items addressing idea generation, technology investments, external information exploitation, ability to renew, and change in operations. 


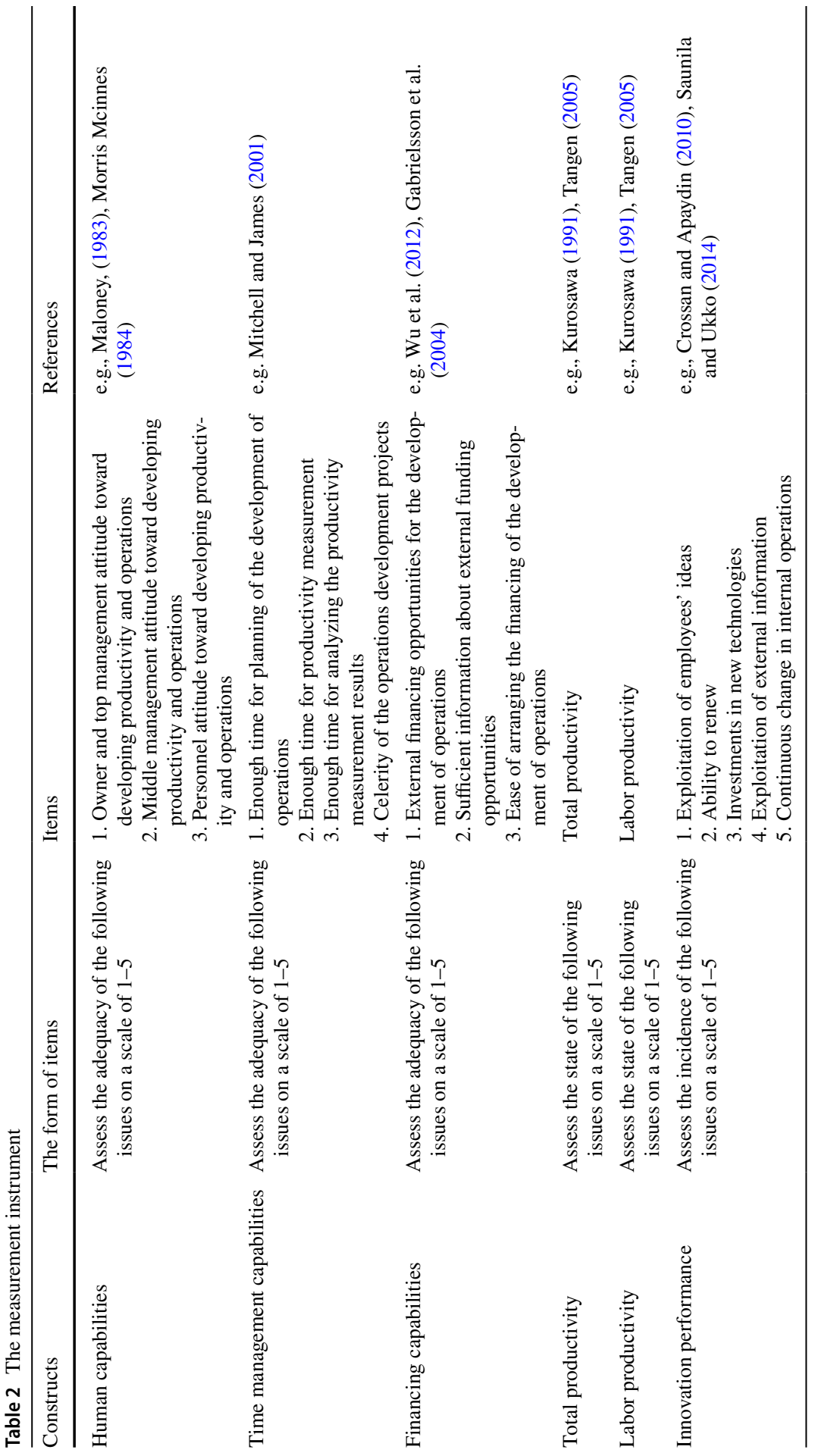


These constructs were operationalized as shown in Table 2. The survey also included controls for contextual variables that might confound the results. Firm size was measured by revenue and number of employees. Firm type was also selected as a control variable, and the respondents were asked to identify their employers either as manufacturing or service firms.

\section{Results}

\subsection{Measurement model}

The normal distribution of each variable was assessed using the measures of kurtosis and skewness. Each variable appeared to have approximately normal distribution. Next, before hypotheses testing, the levels of validity and reliability were assessed. As shown in Table 3, convergent validity was assessed based on item loadings, which were considered to be good (Comrey and Lee 1992) for this sample size (Hair et al. 2010). Also, the average variance extracted (AVE) was higher than 0.5 for each construct, supporting convergent validity. For multicollinearity, the variance inflation factors (VIF) were calculated. All VIFs were less than 3.0, considerably less than the recommended threshold of 5-10, suggesting that multicollinearity was not a problem (Kleinbaum et al. 1988). Discriminant validity was assessed by comparing the square root of the AVE to the shared variance (see the correlation coefficients in Table 4) between each pair of constructs. The lowest AVE was 0.720, and all the coefficients were less than that value, indicating that the constructs possessed discriminant validity. Reliability was assessed using Cronbach's $\alpha$ and composite reliability (CR). Table 3 shows that all constructs had Cronbach's alpha and CR values were more than 0.70 , establishing the reliability and internal consistency of all the constructs. In summary, the results indicated that the theoretical constructs were reliable, valid, and unidimensional, enabling proceeding to hypothesis testing.

\subsection{Hypothesis testing}

The research hypotheses were tested using linear regression analyses. Table 5 presents the results of the regression analyses for operational capabilities, total productivity, labor productivity, and innovation performance. For H1, we found support for H1a and H1b. The model of total productivity was significant $(\mathrm{p}=0.000)$, showing that human $(\beta=0.402, \mathrm{p}=0.000)$ and time management capabilities $(\beta=0.385, p=0.000)$ significantly influenced total productivity. Financing capabilities $(\beta=0.081, p=0.323)$ were not significant in the model. However, firm size, as measured by number of employees, had significant influence on the model. We interpret these observations to show that the influence of operational capabilities on total productivity was not significantly affected by firm type. However, the higher the number of employees was, the stronger the influence of operational capabilities on total productivity was. In sum, the results showed that the 
Table 3 The results of FA and reliability tests

\begin{tabular}{llllll}
\hline Constructs & No of item & Factor loadings & Cronbach's $\alpha$ & CR & AVE \\
\hline Human capabilities & 1 & 0.770 & 0.734 & 0.851 & 0.657 \\
& 2 & 0.889 & & & \\
Time management capabilities & 3 & 0.768 & & & \\
& 2 & 0.874 & 0.834 & 0.893 & 0.684 \\
& 3 & 0.921 & & & \\
Financing capabilities & 4 & 0.897 & & & \\
& 1 & 0.564 & & & \\
Innovation performance & 2 & 0.876 & 0.798 & 0.882 & 0.714 \\
& 3 & 0.811 & & & \\
& 1 & 0.847 & & & \\
& 2 & 0.799 & 0.763 & & \\
& 3 & 0.730 & & & \\
& 4 & 0.691 & & & \\
\hline
\end{tabular}

Table 4 Intercorrelations of the variables

\begin{tabular}{lllllll}
\hline & 1 & 2 & 3 & 4 & 5 & 6 \\
\hline 1. Human capabilities & 1.000 & & & & & \\
2. Time management capabilities & $0.226^{* * *}$ & 1.000 & & & & \\
3. Financing capabilities & 0.082 & $0.231^{* * *}$ & 1.000 & & & \\
4. Total productivity & $0.383^{* * *}$ & $0.340^{* * *}$ & $0.181^{*}$ & 1.000 & & \\
5. Labor productivity & $0.340^{* * *}$ & $0.186^{*}$ & 0.093 & $0.640^{* * *}$ & 1.000 \\
6. Innovation performance & $0.233^{* *}$ & $0.221^{* *}$ & $0.175^{*}$ & 0.060 & 0.132 & 1.000 \\
\hline
\end{tabular}

Sign. $* * * \leq 0.001, * * 0.001<\mathrm{p} \leq 0.01, * 0.01<\mathrm{p} \leq 0.05$

better the human and time management capabilities the firm had, the more likely it was to have high total productivity.

For H2, we found support for H2a. The model of labor productivity was significant $(p=0.006)$ and showed that human capabilities $(\beta=0.332, p=0.001)$ significantly influenced labor productivity. Time management $(\beta=0.169, \mathrm{p}=0.074)$ and financing capabilities $(\beta=0.019, \mathrm{p}=0.814)$ were not significant in the model, and the control variables did not influence it. The influence of operational capabilities on labor productivity, therefore, was not affected by firm size or type. In sum, the results showed that the better human capabilities the firm had, the more likely it was to have high labor productivity.

For $\mathrm{H} 3$, we found support for $\mathrm{H} 3 \mathrm{a}$ and $\mathrm{H} 3 \mathrm{~b}$. The model was significant $(p=0.003)$ and showed that human $(\beta=0.138, p=0.047)$ and time management capabilities $(\beta=0.190, p=0.005)$ significantly influenced innovation 
Table 5 Regression results of total productivity, labor productivity, and innovation performance

\begin{tabular}{|c|c|c|c|c|c|c|}
\hline \multirow[t]{2}{*}{ Dependent variables } & \multicolumn{2}{|c|}{ Total productivity } & \multicolumn{2}{|c|}{ Labor productivity } & \multicolumn{2}{|c|}{$\begin{array}{l}\text { Innovation perfor- } \\
\text { mance }\end{array}$} \\
\hline & $\beta$ & Std. error & $\beta$ & Std. error & $\beta$ & Std. error \\
\hline \multicolumn{7}{|l|}{ Controls } \\
\hline No of employees & $0.003^{*}$ & 0.001 & 0.002 & 0.001 & $-0.002 *$ & 0.001 \\
\hline Revenue & $-6.44 \mathrm{E}-6$ & 0.000 & $-4.37 \mathrm{E}-6$ & 0.000 & $9.76 \mathrm{E}-6$ & 60.000 \\
\hline Firm type & 0.010 & 0.158 & 0.061 & 0.160 & 0.068 & 0.111 \\
\hline \multicolumn{7}{|l|}{ Main effects } \\
\hline Human capabilities & $0.402 * * *$ & 0.100 & $0.332 * * *$ & 0.100 & $0.138 *$ & 0.069 \\
\hline Time management capabilities & $0.385^{* * *} *$ & 0.093 & 0.169 & 0.094 & $0.190 * *$ & 0.066 \\
\hline Financing capabilities & 0.081 & 0.082 & 0.019 & 0.082 & 0.054 & 0.057 \\
\hline \multicolumn{7}{|l|}{ Model summary } \\
\hline $\mathrm{F}$ & $8.395 * * *$ & & $3.182 * *$ & & $3.421 * *$ & \\
\hline $\mathrm{R}^{2}$ & 0.242 & & 0.108 & & 0.119 & \\
\hline Adjusted $\mathrm{R}^{2}$ & 0.213 & & 0.074 & & 0.084 & \\
\hline
\end{tabular}

Sign. $* * * \leq 0.001, * * 0.001<\mathrm{p} \leq 0.01, * 0.01<\mathrm{p} \leq 0.05$

performance. Financing capabilities $(\beta=0.054, \mathrm{p}=0.345)$ were not significant in the model. Also, firm size, as measured by number of employees, had significant influence on the model. These results meant that the lower the number of employees was, the stronger the influence of operational capabilities on innovation performance was. To sum up, the results showed that the better human and time management capabilities the firm had, the more likely the firm was to succeed in innovation performance. The summary of hypothesis test results is presented in Table 6.

\section{Discussion and conclusions}

\subsection{Theoretical contributions}

In this article, we present empirical validation of the prerequisites of productivity and innovation, which are important components of competitive advantages. In this research, we add three preceding operational capabilities-human, time management, and financing capabilities - as a means to establish operational capabilities. We also add to the literature a comprehensive investigation of the links of preceding operational capabilities with productivity (i.e., total productivity and labor productivity) and innovation performance. The study makes three main contributions to operational capabilities research.

First, the study indicates that human capabilities have significant impacts on total productivity, labor productivity, and innovation performance. It seems that manager and employee commitment both play major roles in increasing total productivity. The results thus support previous studies highlighting labor attitudes and 
Table 6 Summary of hypothesis test results

\begin{tabular}{lll}
\hline Hypothesis & p value & Hypothesis support \\
\hline H1a: Human capabilities are positively related to total productivity & $0.000^{* * *}$ & Supported \\
H1b: Time management capabilities are positively related to total & $0.000^{* * *}$ & Supported \\
productivity & & \\
H1c: Financing capabilities are positively related to total productivity & 0.323 & Not supported \\
H2a: Human capabilities are positively related to labor productivity & $0.001^{* * *}$ & Supported \\
$\begin{array}{l}\text { H2b: Time management capabilities are positively related to labor } \\
\text { productivity }\end{array}$ & 0.074 & Not supported \\
$\begin{array}{l}\text { H2c: Financing capabilities are positively related to labor productivity } \\
\text { H3a: Human capabilities are positively related to innovation perfor- } \\
\text { mance }\end{array}$ & 0.814 & Not supported \\
$\begin{array}{l}\text { H3b: Time management capabilities are positively related to innovation } \\
\text { performance }\end{array}$ & $0.005^{* *}$ & Supported \\
$\begin{array}{l}\text { H3c: Financing capabilities are positively related to innovation perfor- } \\
\text { mance }\end{array}$ & 0.345 & Not supported \\
\hline
\end{tabular}

Sign. $* * * \leq 0.001, * * 0.001<\mathrm{p} \leq 0.01, * 0.01<\mathrm{p} \leq 0.05$

commitment as important drivers of organizational and job performance (Collins and Smith 2006 Jiang et al. 2012; Melián-González 2016; Morris 2018). In line with Wu et al. (2010), commitment, manifested in employee attitudes and constituting a central element of human capabilities, seems to affect the actions and reactions of managers and employees, which, in turn, are associated with specific processes and practices that improve organization performance and productivity.

Several points regarding the significant impact of managers and employees' attitudes on labor productivity warrant discussion. The results support the findings of Ployhart et al. (2011) suggesting that human capabilities serve as a foundation for performance through commitment to developing additional abilities. These findings may also confirm research indicating that employees across organizational levels aim to increase their productivity by learning new skills and applying knowledge related to their jobs (Onkelinx et al. 2016; Ukko et al. 2017) because the training practices that support labor commitment have positive effects on job performance (Latorre et al. 2016). Additionally, a significant relationship is found between innovation performance and the capabilities of managers and employees. These results align with Saunila and Ukko's (2014) finding that human capabilities are related to employee commitment and affect innovation performance. As well, HernandezEspallardo et al. (2018) report that labor's job-related attitudes play a significant role in creating an innovation culture. The scope of the items addressing human capabilities in this study is quite narrow, so future research could focus on the drivers of commitment and attitudes among employees across organizational levels.

Second, the study indicates that time management capabilities have significant impacts on total productivity and innovation performance but not labor productivity. Regarding total productivity, the study supports the findings of Mitchell and James (2001) and Ritala et al. (2016) by identifying time as an important component of operational capabilities and by showing that, when given little time to identify 
and solve firm problems, managers see time management as an essential capability. Regarding labor productivity, for instance, Reunanen (2015) describes the high reliance of employee productivity and firm performance on time management in different tasks. However, a connection between time management capabilities and labor productivity is not found in this study. A possible explanation is that there are standard times for different tasks, which leave little room for improvement.

Third, the study indicates that financing capabilities have no significant impact on total productivity, labor productivity, or innovation performance. The development of firm productivity and innovation performance seems to rely more on the other preceding operational capabilities than financing capabilities. When developing productivity and innovation performance, therefore, firms should focus on increasing the commitment of employees and managers at all organizational levels, as well as allowing time for productivity improvement and innovation activities. This result is surprising because financial constraints are believed to prevent organizations from improving productivity (Restuccia and Rogerson 2013) and managing innovation performance (Mazzucato 2013; Mina et al. 2013). In this study, the empirical data were gathered from Finland, so the results may be different in other emerging markets, which could be a relevant topic for further research. Further, regarding the control variables, increasing the number of employees has significant, positive impacts on total productivity and negative impacts on innovation performance. These issues are not hypothesized in this study but may also be interesting topics for further research.

\subsection{Practical contributions}

Our findings have implications for both managers and policymakers. SME managers can benefit from understanding the determinants of productivity and innovation. Given the influence of human capabilities on total and labor productivity, employees should be supported in their tasks. In addition to incentives to increase their workload, therefore, employees should receive support to strengthen their commitment and positive attitudes toward work, which seem largely neglected today. Innovation performance can be improved if enough time is given to innovation development. Further, to fully realize operational capabilities, firms should attend to their preceding capabilities. Investing in such capabilities should include supporting human commitment, allowing enough time to complete tasks, and finding financing opportunities. Consequently, firms aiming to improve productivity and innovation should focus on certain preceding operational capabilities. From policymakers' perspective, our results suggest that public support could be more effective at encouraging firm productivity and innovation development than other policy instruments, such as legislation.

\subsection{Limitation and further research}

There are three major limitations in our study. The first limitation of our analysis is related to the sample. The study was conducted among Finnish SMEs, so the results 
may differ in other contexts. Country-specific characteristics, therefore, should be taken into account when applying the results in practice or further research. Future studies could address these sample-related limitations by validating the results in different regions using different methodologies. Second, the used measures may cause limitations and the measures should be validated with additional research. Third, the use of perceptual data is another limitation of the research, although perceived measures are found to have positive correlations with objective measures (e.g., Venkatraman and Ramanujan 1987). Also, formal procedures and policies do not always correspond with firms' operations. The reality of daily experience is more truthful. Given the studied constructs, perceptual data are considered to be appropriate to obtain truthful views.

Acknowledgements Open access funding provided by LUT University.

Open Access This article is distributed under the terms of the Creative Commons Attribution 4.0 International License (http://creativecommons.org/licenses/by/4.0/), which permits unrestricted use, distribution, and reproduction in any medium, provided you give appropriate credit to the original author(s) and the source, provide a link to the Creative Commons license, and indicate if changes were made.

\section{References}

Abolhassani A, Harner EJ, Jaridi M (2019) Empirical analysis of productivity enhancement strategies in the North American automotive industry. Int J Prod Econ 208:140-159

Adams-Bigelow M, Griffin A (2005) Product development cycle time and success: new results from PDMA's comparative performance assessment study. In: PDMA Research Forum

Amaral PS, Quintin E (2010) Limited enforcement, financial intermediation, and economic development: a quantitative assessment. Int Econ Rev 51(3):785-811

Ancona D, Chong CL (1996) Entrainment: pace, cycle, and rhythm in organizational behavior. Res Organ Behav 18:251-284

Banerjee AV, Moll B (2010) Why does misallocation persist? Am Econ J 2(1):189-206

Barbosa N, Silva F (2018) Public financial support and firm-specific characteristics: evidence from Portugal. Eur Plan Stud 26(4):670-686

Barney JB, Wright PM (1998) On becoming a strategic partner: the role of human resources in gaining competitive advantage. Hum Resour Manag 37(1):31-46

Bergkvist L, Rossiter JR (2007) The predictive validity of multiple-item versus single-item measures of the same constructs. J Mark Res 44(2):175-184

Bergkvist L, Rossiter JR (2009) Tailor-made single-item measures of doubly concrete constructs. Int J Advert 28(4):607-621

Berglund M, Karltun J (2007) Human, technological and organizational aspects influencing the production scheduling process. Int J Prod Econ 110(1-2):160-174

Blackburn J (2012) Valuing time in supply chains: establishing limits of time-based competition. J Oper Manag 30(5):396-405

Buera FJ, Kaboski JP, Shin Y (2011) Finance and development: a tale of two sectors. Am Econ Rev 101(5):1964-2002

Calantone R, Garcia R, Dröge C (2003) The effects of environmental turbulence on new product development strategy planning. J Prod Innov Manag 20(2):90-103

Carayannis EG, Alexander J (2002) Is technological learning a firm core competence, when, how and why? A longitudinal, multi-industry study of firm technological learning and market performance. Technovation 22(10):625-643

Castillo V, Maffioli A, Rojo S, Stucchi R (2014) The effect of innovation policy on SMEs' employment and wages in Argentina. Small Bus Econ 42(2):387-406 
Chan CL, Jiang JJ, Klein G (2008) Team task skills as a facilitator for application and development skills. IEEE Trans Eng Manag 55(3):434-441

Chen J, Reilly RR, Lynn GS (2012) New product development speed: too much of a good thing? J Prod Innov Manag 29(2):288-303

Collins CJ, Smith KG (2006) Knowledge exchange and combination: the role of HR practices in the performance of high-technology firms. Acad Manag J 49(3):544-560

Comrey AL, Lee HB (1992) A first course in factor analysis, 2nd edn. Lawrence Erlbaum Associates, Hillsdale

Craighead CW, Ketchen DJ, Dunn KS, Hult GTM (2011) Addressing common method variance: guidelines for survey research on information technology, operations, and supply chain management. IEEE Trans Eng Manag 58(3):578-588

Crossan MM, Apaydin M (2010) A multi-dimensional framework of organizational innovation: a systematic review of the literature. J Manag Stud 47(6):1154-1191

d'Andria D, Savin I (2018) A win-win-win? Motivating innovation in a knowledge economy with tax incentives. Technol Forecast Soc Change 127:38-56

Dangol R, Kos A (2014) Knightian uncertainty and risk: a basis for untangling dynamic capabilities from operational capabilities. J Strategy Manag 7(4):337-353

Davila T, Epstein M, Shelton R (2012) Making innovation work: How to manage it, measure it, and profit from it. FT Press, Upper Saddle River

De Brentani U, Kleinschmidt EJ (2004) Corporate culture and commitment: impact on performance of international new product development programs. J Prod Innov Manag 21(5):309-333

De Brentani U, Kleinschmidt EJ (2015) The impact of company resources and capabilities on global new product program performance. Project Manag J 46(1):12-29

De Negri JA, Maffioli A, Rodriguez CM, Vázquez G (2011) The impact of public credit programs on Brazilian firms (No. IDB-WP-293). IDB Working Paper Series

De Toni A, Meneghetti A (2000) Traditional and innovative paths towards time-based competition. Int J Prod Econ 66(3):255-268

De Winne S, Marescaux E, Sels L, Van Beveren I, Vanormelingen S (2018) The impact of employee turnover and turnover volatility on labor productivity: a flexible non-linear approach. Int J Hum Resour Manag. https://doi.org/10.1080/09585192.2018.1449129

Del Canto JG, Gonzalez IS (1999) A resource-based analysis of the factors determining a firm's R\&D activities. Res Policy 28(8):891-905

Demeter K (2013) Time-based competition-the aspect of partner proximity. Decis Support Syst 54(4):1533-1540

Diamantopoulos A, Sarstedt M, Fuchs C, Wilczynski P, Kaiser S (2012) Guidelines for choosing between multi-item and single-item scales for construct measurement: a predictive validity perspective. J Acad Mark Sci 40(3):434-449

Eisenhardt KM (1989) Making fast strategic decisions in high-velocity environments. Acad Manag J 32(3):543-576

Eisenhardt KM, Martin JA (2000) Dynamic capabilities: what are they? Strateg Manag J 21(10/11):1105-1121

Ellwood P, Grimshaw P, Pandza K (2017) Accelerating the innovation process: a systematic review and realist synthesis of the research literature. Int J Manag Rev 19(4):510-530

Ferdows K, De Meyer A (1990) Lasting improvements in manufacturing performance: in search of a new theory. J Oper Manag 9(2):168-184

Flynn BB, Flynn EJ (2004) An exploratory study of the nature of cumulative capabilities. J Oper Manag 22(5):439-457

Flynn BB, Wu SJ, Melnyk S (2010) Operational capabilities: hidden in plain view. Bus Horiz 53(3):247-256

Fonseca T, Lima F, Pereira SC (2018) Understanding productivity dynamics: a task taxonomy approach. Res Policy 47(1):289-304

Gabrielsson M, Sasi V, Darling J (2004) Finance strategies of rapidly-growing Finnish SMEs: born Internationals and Born Globals. Eur Bus Rev 16(6):590-604

Gerhart B, Milkovich GT (1992) Employee compensation: research and practice. In: Dunnette MD, Hough LM (eds) Handbook of industrial and organizational psychology, vol 3. Consulting Psychologists Press, Palo Alto, pp 481-569

Goshu YY, Matebu A, Kitaw D (2017) Development of productivity measurement and analysis framework for manufacturing companies. J Optim Ind Eng 10(22):1-13 
Grilli L, Mazzucato M, Meoli M, Scellato G (2018) Sowing the seeds of the future: policies for financing tomorrow's innovations. Technol Forecast Soc Chang 127:1-7

Gutierrez-Gutierrez LJ, Barrales-Molina V, Kaynak H (2018) The role of human resource-related quality management practices in new product development: a dynamic capability perspective. Int J Oper Prod Manag 38(1):43-66

Hair JF Jr, Black WC, Babin BJ, Anderson RE (2010) Multivariate data analysis: a global perspective, 7 th edn. Prentice-Hall, Upper Saddle River

Helfat CE, Winter SG (2011) Untangling dynamic and operational capabilities: strategy for the (n)everchanging world. Strateg Manag J 32(11):1243-1250

Hernandez-Espallardo M, Osorio-Tinoco F, Rodriguez-Orejuela A (2018) Improving firm performance through inter-organizational collaborative innovations: the key mediating role of the employee's job-related attitudes. Manag Decis 56:1167-1182

Holzer HJ (1987) Hiring procedures in the firm: Their economic determinants and outcomes. In: Block $\mathrm{R}$ et al (eds) Human resources and firm performance. Industrial Relations Research Association, Madison

Huselid MA (1995) The impact of human resource management practices on turnover, productivity, and corporate financial performance. Acad Manag J 38(3):635-672

Jacobs BW, Kraude R, Narayanan S (2016) Operational productivity, corporate social performance, financial performance, and risk in manufacturing firms. Prod Oper Manag 25(12):2065-2085

Jerzmanowski M (2007) Total factor productivity differences: appropriate technology vs. efficiency. Eur Econ Rev 51(8):2080-2110

Jiang K, Lepak DP, Hu J, Baer JC (2012) How does human resource management influence organizational outcomes? A meta-analytic investigation of mediating mechanisms. Acad Manag J 55(6):1264-1294

Jiménez-Jiménez D, Sanz-Valle R (2011) Innovation, organizational learning, and performance. J Bus Res 64(4):408-417

Johnston R, Brignall S, Fitzgerald L (2002) Good enough' performance measurement: a trade-off between activity and action. J Oper Res Soc 53(3):256-262

Kacperczyk M, Nieuwerburgh SV, Veldkamp L (2014) Time-varying fund manager skill. J Financ 69(4):1455-1484

Karadag H (2015) Financial management challenges in small and medium-sized enterprises: a strategic management approach. Emerg Mark J 5(1):26

Kessler EH, Bierly PE (2002) Is faster really better? An empirical test of the implications of innovation speed. IEEE Trans Eng Manag 49(1):2-12

Kleinbaum DG, Kupper LL, Muller KE (1988) Applied regression analysis and other multivariate analysis methods. PWS-Kent Publishing Company, Boston

Koufteros X, Verghese AJ, Lucianetti L (2014) The effect of performance measurement systems on firm performance: a cross-sectional and a longitudinal study. J Oper Manag 32(6):313-336

Kurosawa K (1991) Productivity measurement and management at the company level: the Japanese Experience. Elsevier Science Publishers B.V., Amsterdam

Latorre F, Guest D, Ramos J, Gracia FJ (2016) High commitment HR practices, the employment relationship and job performance: a test of a mediation model. Eur Manag J 34(4):328-337

Lee H, Kelley D (2008) Building dynamic capabilities for innovation: an exploratory study of key management practices. R \& D Manag 38(2):155-168

Lee N, Sameen H, Cowling M (2015) Access to finance for innovative SMEs since the financial crisis. Res Policy 44(2):370-380

Liao L, Zhang X, Zhang Y (2017) Mutual fund managers' timing abilities. Pac Basin Financ J 44:80-96

Löfsten H (2016) Organisational capabilities and the long-term survival of new technology-based firm. Eur Bus Rev 28(3):312-332

Loo R (2002) A caveat on using single-item versus multiple-item scales. J Manag Psychol 17(1):68-75

Lv DD, Zeng P, Lan H (2018) Co-patent, financing constraints, and innovation in SMEs: an empirical analysis using market value panel data of listed firms. J Eng Technol Manag 48:15-27

Maire J-L, Bronet V, Pillet M (2005) A typology of 'best practices' for a benchmarking process. Benchmarking 12(1):45-60

Maloney WF (1983) Productivity improvement: the influence of labor. J Constr Eng Manag 109(3):321-334

Mazzucato M (2013) Financing innovation: creative destruction vs. destructive creation. Ind Corp Change 22(4):851-867 
Melián-González S (2016) An extended model of the interaction between work-related attitudes and job performance. Int J Prod Perform Manag 65(1):42-57

Mina A, Lahr H, Hughes A (2013) The demand and supply of external finance for innovative firms. Ind Corp Change 22(4):869-901

Mitchell TR, James LR (2001) Building better theory: time and the specification of when things happen. Acad Manag Rev 26(4):530-547

Morris DM (2018) Innovation and productivity among heterogeneous firms. Res Policy 47(10):1918-1932

Morris Mcinnes J (1984) Corporate management of productivity—an empirical study. Strateg Manag J 5(4):351-365

Onkelinx J, Manolova TS, Edelman LF (2016) The human factor: investments in employee human capital, productivity, and SME internationalization. J Int Manag 22(4):351-364

Peng DX, Schroeder RG, Shah R (2008) Linking routines to operations capabilities: a new perspective. J Oper Manag 26(6):730-748

Perlow LA, Okhuysen GA, Repenning NP (2002) The speed trap: exploring the relationship between decision making and temporal context'. Acad Manag J 45(5):931-955

Piening EP, Salge TO (2015) Understanding the antecedents, contingencies, and performance implications of process innovation: a dynamic capabilities perspective. J Prod Innov Manag 32(1):80-97

Ployhart RE, Van Iddekinge CH, MacKenzie WI Jr (2011) Acquiring and developing human capital in service contexts: the interconnectedness of human capital resources. Acad Manag J 54(2):353-368

Podsakoff PM, MacKenzie SB, Lee JY, Podsakoff NP (2003) Common method biases in behavioral research: a critical review of the literature and recommended remedies. J Appl Psychol 88(5):879

Prieger JE (2007) Regulatory delay and the timing of product innovation. Int J Ind Organ 25(2):219-236

Protogerou A, Caloghirou Y, Lioukas S (2011) Dynamic capabilities and their indirect impact on firm performance. Ind Corp Change 21(3):615-647

Restuccia D, Rogerson R (2013) Misallocation and productivity. Rev Econ Dyn 16(1):1-10

Reunanen T (2015) Human Factor in time management. Procedia Manuf 3:709-716

Ritala P, Heiman B, Hurmelinna-Laukkanen P (2016) The need for speed-unfamiliar problems, capability rigidity, and ad hoc processes in organizations. Ind Corp Change 25(5):757-777

Sackett PR, Larson JR Jr (1990) Research strategies and tactics in industrial and organizational psychology. In: Dunnette MD, Hough LM (eds) Handbook of industrial and organizational psychology, vol 1, 2nd edn. Consulting Psychologists Press, Palo Alto, pp 419-489

Sanchez OP, Terlizzi MA (2017) Cost and time project management success factors for information systems development projects. Int J Project Manag 35(8):1608-1626

Sarstedt M, Wilczynski P (2009) More for less? A comparison of single-item and multi-item measures. Die Betriebswirtschaft 69(2):211

Saunila M (2017) Innovation capability in achieving higher performance: perspectives of management and employees. Technol Anal Strateg Manag 29(8):903-916

Saunila M, Mäkimattila M (2018) A dynamic learning perspective on innovation control: balancing freedom and constraint. In: Vrontis D, Weber Y, Thrassou A, Shams R, Tsoukatos E (eds) Innovation and capacity building_cross-disciplinary management theories for practical applications, Palgrave Studies in Cross-Disciplinary Business Research, in Association with EuroMed Academy of Business. Palgrave MacMillan, London

Saunila M, Ukko J (2014) Intangible aspects of innovation capability in SMEs: impacts of size and industry. J Eng Technol Manag 33:32-46

Schumpeter JA (1934) The theory of economic development: an inquiry into profits, capital, credit, interest, and the business cycle. Transaction Publishers, New Brunswick

Shaw JD, Park T, Kim E (2013) A resource-based perspective on human capital losses, HRM investments and organizational performance. Strateg Manag J 34(5):572-589

Sink D (1985) Productivity management: planning, measurement and evaluation, control and improvement. Wiley, New York, p 518

Stalk JG, Webber AM (1993) Japan's dark side of time. Harvard Bus Rev 71(4):93-102

Swink M, Hegarty HW (1998) Core manufacturing capabilities and their links to product differentiation. Int J Oper Prod Manag 18(4):374-396

Tangen S (2005) Demystifying productivity and performance. Int J Prod Perform Manag 54(1):34-46

Teece DJ, Pisano G, Shuen A (1997) Dynamic capabilities and strategic management. Strateg Manag J 8(7):509-533 
Tornow W, Wiley J (1991) Service quality and management practices: a look at employee attitudes, customer satisfaction, and bottom line consequences. Hum Resour Plan 14:105-115

Tu Q, Vonderembse MA, Ragu-Nathan TS, Sharkey TW (2006) Absorptive capacity: enhancing the assimilation of time-based manufacturing practices. J Oper Manag 24(5):692-710

Ukko J, Tenhunen J, Rantanen H (2007) Performance measurement impacts on management and leadership_-perspectives of management and employees. Int J Prod Econ 110(1-2):39-51

Ukko J, Hildén S, Saunila M, Tikkamäki K (2017) Comprehensive performance measurement and management-innovativeness and performance through reflective practice. J Account Organ Change 13(3):425-448

Ulusoy G, Ikiz I (2001) Benchmarking best manufacturing practices: a study into four sectors of Turkish industry. Int J Oper Prod Manag 21(7):1020-1043

Venkatraman N, Ramanujan V (1987) Planning system success: a conceptualization and an operational model. Manag Sci 33(6):687-705

Vos E, Yeh AJY, Carter S, Tagg S (2007) The happy story of small business financing. J Bank Financ 31(9):2648-2672

Whitehead JC, Groothuis PA, Blomquist GC (1993) Testing for non-response and sample selection bias in contingent valuation: analysis of a combination phone/mail survey. Econ Lett 41(2):215-220

Wu SJ, Melnyk SA, Flynn BB (2010) Operational capabilities: the secret ingredient. Decis Sci 41(4):721-754

Wu SJ, Melnyk SA, Swink M (2012) An empirical investigation of the combinatorial nature of operational practices and operational capabilities: compensatory or additive? Int J Oper Prod Manag 32(2):121-155

Xiang D, Chen J, Tripe D, Zhang N (2018) Family firms, sustainable innovation and financing cost: evidence from Chinese hi-tech small and medium-sized enterprises. Technol Forecast Soc Change 144:499-511

Publisher's Note Springer Nature remains neutral with regard to jurisdictional claims in published maps and institutional affiliations. 